\title{
DISCOVERY
}

\section{in Physics}

The Cambridge Physical Tracts are up-to-date reports from research workers in fields where progress is particularly rapid and where a complete study is not yet possible. About a dozen of these tracts are in preparation and the four following have already appeared, price $6 s$. net each.

\section{NEGATIVE IONS by H. S. W. MaSSEy, Ph.D.}

An account of recent research, by experiment and the application of quantum theory, into the nature and properties of negative ions.

2. THE MOBILITY OF POSITIVE IONS IN GASES by Professor A. M. TYNDALL, D.Sc., F.R.S.

The story of recent work in the H. H. Wills Physical Laboratory at Bristol, why it was undertaken and with what results.

\section{SUPERCONDUCTIVITY by D. Shoenberg, Ph.D.}

No satisfactory theory of metals, which will explain the phenomenon of superconductivity, has yet been formulated. The work described here makes it clear what any such theory will have to explain.

4. ELECTRON OPTICS by the Research Staff of Electric and Musical Industries Ltd., compiled and edited by OTTO KLEMPERER.

A concise account of the principles and methods of geometrical electron optics, and its technical applications to television and electron microscopy.

\section{Mathematics for Mathematicians}

ELEMENTS OF THE TOPOLOGY OF PLANE SETS OF POINTS by M. H. A. Newman, M.A., F.R.S.

$12 s .6 d$. net

An introduction to the methods of Topology which makes accessible to analysts the simple modern technique for proving the theorems on sets of points required in the theory of functions of a complex variable.

\section{CAMBRIDGE UNIVERSITY PRESS}




\section{O N T E N T S}

Grünwald, GézA. Zur Summabilitätstheorie der Fourierschen Doppelreihe. (With 2 Figures in the Text)

RANkIv, R. A. Contributions to the theory of Ramanujan's function $\tau(n)$ and similar arithmetical functions. I. The zeros of the function $\sum_{n=1}^{\infty} \frac{\tau(n)}{n^{n}}$ on the line $\Re_{s}=\frac{1,3}{2}$

RANkIN, R. A. Contributions to the theory of Ramanujan's function $\tau(n)$ and similar arithmetical functions. II. The order of the Fourier coefficients of integral modular forms .

Dickinson, D. R. On the derivation of discontinuous functions. (With 1 Figure in the Text)

MaItuAND, B. J. A note on functions regular and bounded in the unit circle and small at a set of points near the circumference of the circle. (With 1 Figure in the Text) . $\quad . \quad$. $\quad . \quad . \quad . \quad . \quad . \quad .382$

MACPHERSON, R. E. Canonical systems on a reducible variety _ . . . 389

Carslaw, H. S. and JAeger, J. C. A problem in conduction of heat. (With 2 Figures in the Text)

Hoyle, F. and Lytrueton, R. A. The effect of interstellar matter on climatic variation. (With 1 Figure in the Text) . . . . . . . 405

Drrac, P. A. M. A new notation for quantum mechanics . . . . . 416

HOYLE, F. Quantum electrodynamics. I. . . . . . . . . 419

HOYLE, F. Quantum electrodynamic8. II. . . . . . . . . 438

MAssey, H. S. W. and Corben, H. C. Elastic collisions of mesons with electrons and protons . . . . . . . . . . . . .

Goodwin, E. T. Electronic states at the surfaces of crystals. IV. The activation of adsorbed atoms by surface electrons . . . . . .

Lennard-Jones, J. E., Wrukes, M. V. and Bratt, J. B. The design of a small differential analyser. (With 4 Figures in the Text) . . . . .

Buacketr, P. M. S. and Wrinings, F. C. An automatic curve follower for use with the differential analyser. (With 14 Figures in the Text) . . .

Wrunsms, F. C. A reversible head for the automatic curve following device. (With 4 Figures in the Text) . . . . . . . . 506

Wrilams, E. J. Note on the sensitive time of a Wilson expansion chamber . 512

RESEARCH NOTES:

TODD, J. A. A remark on a theorem of Severi . . . . . . 516

BATH, F. On circles determined by five lines in a plane . . . . 518

JEFFREY8, HAROLD. The minimum $\chi^{2}$ approximation . . . 520

Chalmers, J. Alan. Note on the calculation of the Peltier effect . . 521

WARD, A. G. The half-value period of ${ }^{13} \mathrm{~N}$. . . . . . . 523

LONDON: CAMBRIDGE UNIVERSITY PRESS

INDLA: MACMILLAN TOKYO: MARUZEN COMPANY LDITED

PRINTED IN GREAT BRITANN BY W. LEWI8, M.A., AT THE UNIVERBTTY PRE88, CAMBRTDGE 